\title{
Fire Safety Science in Germany: A Status Report about Research Activities and Requirements
}

\author{
REINHARD GRABSKI \\ Institute of Fire Department Saxony-Anhalt \\ Biederitzer Str. 5, D-39175 Heyrothsberge, Germany
}

\begin{abstract}
The system of fire protection in Germany is explained from the historic point of view. A network of decentralized independent stakeholders with their own responsibility has been developed here. This one is also reflected in research related to the specific field. This system is qualified to guarantee a high level of people's protection and copes with the requirements of industry. Thus, mostly smaller teams are established in German fire research, which have their own individual profiles. An overview is given about the work and technical opportunities of these institutions. In doing so, institutions that solely test for standard compliance were not considered. To encourage cooperation between these institutions as well as with the industry and end users, the German Fire Protection Association offers an important platform for discussion.
\end{abstract}

KEYWORDS: Germany, fire research, fire protection, status and progress

\section{SHORT HISTORICAL BACKGROUND}

Germany is a country with long tradition in fire safety [1], [2]. Already in the second half of the $19^{\text {th }}$ century, the time of industrialization, the first fire brigades were founded. In 1841, the first volunteer fire brigade called "Freiwilliges Lösch- und Rettungscorps” was established in the German city Meißen, a town in Saxony. This was the beginning of a successful system with volunteers that guarantees up to now fire protection covering the whole country. Even earlier, some cities had organizations dedicated to fire protection. These units or groups were founded as part of insurance agencies, in former times called "Brandkassen". The oldest one was the "Hamburger Feuerkasse" in the big seaport city Hamburg, established in 1728. Caused by devastating fire disasters, e.g. in Hamburg in 1842, people started to think about more fire safety and therefore more public activities.

In parallel to volunteers, professional fire brigades were created. The first one was founded in Berlin in 1851, a powerful growing city in these years [3]. In twenty years the population doubled. The cramped style of construction as well as the industrialization led to a higher danger level and increased fire risks. The fundamental ideas of fire fighting and tactics, like alerting the fire fighters, reducing reaction time, and organizing short ways, were born by the fire chief Ludwig Scabell. So, the Berlin system of fire fighting became the standard model in Germany.

At the end of the $19^{\text {th }}$ century, the industrial revolution caused new threats as well as new technical opportunities for extinguishing equipment. The motorization of pumps and vehicles was significant. Since 1863, the situation in Germany was characterized by steam hoses. In 1902, the first automobile unit in the world was put into action in a professional fire brigade. In the twenties and thirties, important technological steps were accomplished. Here, one should name the first vehicle with a turntable ladder in 1932 and the application of foam and powder for fire extinguishing.

Up to now, there was a continuous development such that a high level of safety could be reached in Germany. For example, this can be seen at the big international industrial fair of fire services INTERSCHUTZ “Der rote Hahn”, which usually takes place every five years in Hanover. Step by step the technological development in fire protection was interspersed with scientific methods. An association with this focus was founded in Stuttgart in 1950. It included all groups concerned with fire protection in Germany and continued the tradition started before the Second World War. Additionally, the fire protection should be supported by scientific assistance and practical measures [4].

This organization is the "Vereinigung zur Förderung des deutschen Brandschutzes" (vfdb), the German Fire Protection Association. It edits a scientific fire protection journal in German language, organizes an annual fire protection conference with about 500 - 800 participants (conference language is German), and publishes instructions for German fire fighters as guidelines, leaflets, technical reports, and other position papers. Besides these activities for the further development of German fire protection, the vfdb makes 
multiple efforts to form international contacts in order to take into account the globalization of risks, industrial activities, and society in general.

With the new beginning after the war, different other organizational structures were established. The most important one is the "Deutscher Feuerwehrverband (DFV)", the German Fire Fighters' Federation, newly founded in 1952. It represents all fire fighters, the professional as well as the volunteers. Furthermore, the latter are also organized in federations on the state level [5]. During the cold war, fire protection was developed in both political systems - or rather in both German countries - in a different manner. Now, after the unification, the organizational structures in fire protection are once again uniform.

Likewise, 50 years ago, several fire science institutions as well as different chairs and courses of studies at universities were founded working on different partial areas of fire and combustion. These different research groups are still working independently and on their own responsibility so far.

\section{STATISTICAL ANALYSIS}

Statistical information is fundamental for decisions in each country. Therefore, in Germany, it is very problematic that comprehensive and sound data is not available for fire fighting and fire protection. The main reason for this is that responsibility for fire protection is given the local authorities in the German federal political structure. Nevertheless, the central government regulates parts of the disaster control and the civil defense. However, the legislation of building regulations is again decentralized on the state level. Therefore, many different rules and bylaws for fire prevention exist in Germany which is confusing not only for foreign observers of the scene.

Of course insurance agencies as well as the fire fighters' federation possess their own collected data, which is necessary for respective decisions [6] - [7]. The professional fire services are now developing statistics which are based on the principle of so called "microcensus", i.e. representative selection. This work is sponsored and promoted by the German Fire Protection Association (vfdb) and carried out by the Berlin fire brigade. By the way, currently, the best practice of unusual fire fighters' attacks (or more correctly "bad practice") is saved in databases in German language (e.g. see www.bestpractice-feuerwehr.de).

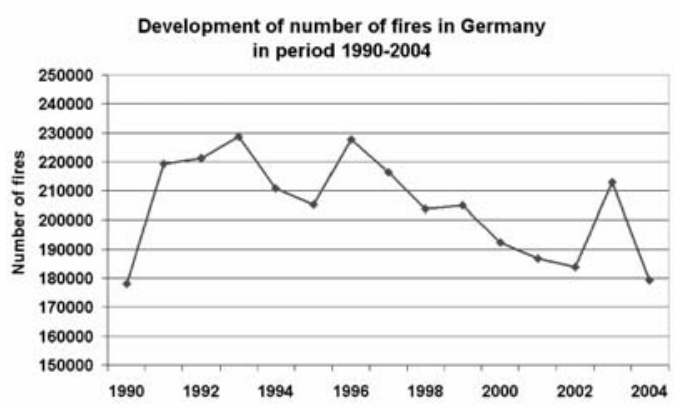

Fig. 1. The number of fires in Germany.

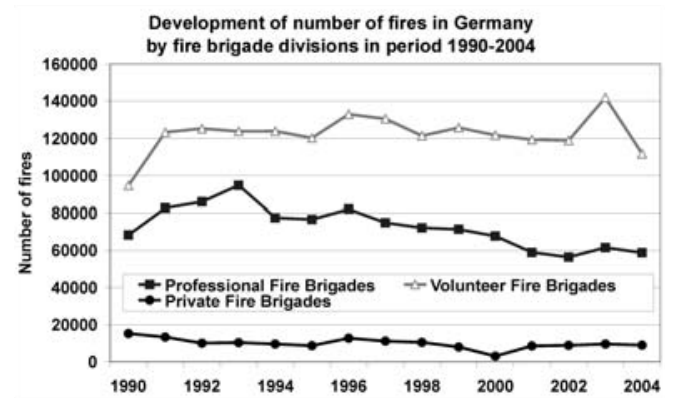

Fig. 2. The number of attacks separated by type of fire brigade.

In the following, the German situation of fire risks and their consequences is analyzed in this way. Let us start in the year of unification, which was on October 3, 1990. After a short period of changing conditions as a result of this event, the number of fires was stable with slowly decreasing tendency (see Fig. 1). This is an indication of a high level in fire protection, such that only further minor improvements can be expected. The main part of fire fighting is done by volunteers (see Fig. 2). This guarantees a short arrival time and often minor losses. On the other hand the professional fire fighters are located in big cities and areas of industrial concentration. About $5 \%$ of fires are characterized as major events and about $13 \%$ of fires are middle events in Germany. As a comparison, the number of professional fire fighters is 28,056 in contrast to $1,042,435$ volunteer fire fighters in 2005 . The private fire brigades $(31,259)$ are directly employed by the companies they protect. Naturally there is a close cooperation between these three groups. These numbers are only the members in active service.

A similar result is present for fire deaths (see Fig. 3). It is interesting that the share of male victims is higher than this of female. It is also important that this number is approximately constant in the last years even 
though the number of old and ill people is increasing in German society due to demographic changes. Most of the fires are in dwellings (about 80 to $85 \%$ ). It is a peculiar situation that in spite of this fact no bylaw or obligatory rule for home smoke detectors exists in all German states so far. The reason is not technical but political because public authorities want to "deregulate" as much as possible.

Finally, it is shown in Fig. 4 how much insurance agencies had to pay in the case of major losses. There is no clear tendency but annual fluctuation. The mean value over 13 years is about 1 billion Euros. This number includes different disasters, most notably the big flood in the year 2002. The total costs for fires are declared by insurance agencies with 1.241 billion Euros in 2005 .

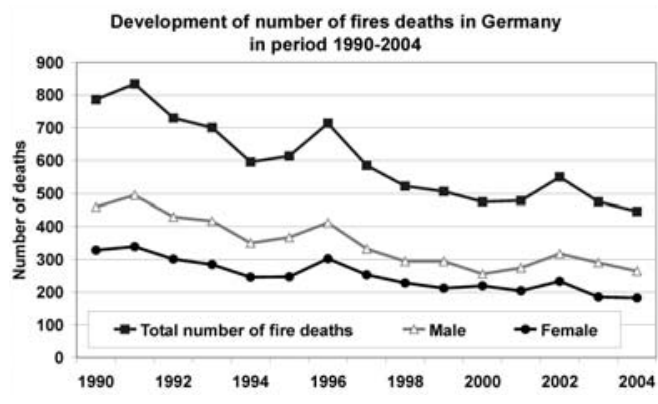

Fig. 3. Fire deaths in Germany.

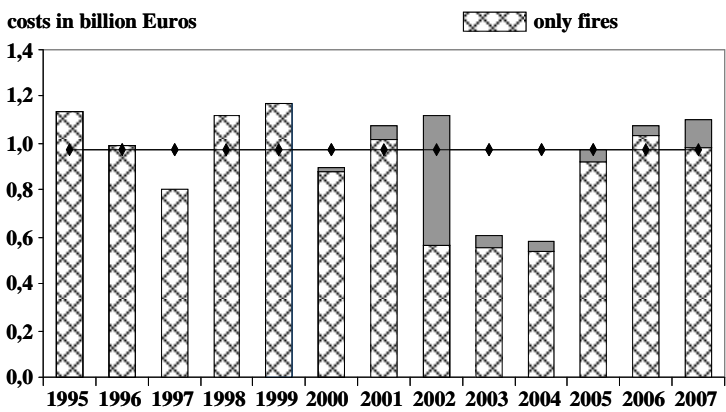

Fig. 4. Insurance costs for major losses.

\section{GERMAN NETWORK IN FIRE PROTECTION}

In order to assess the fire research in Germany you have to look at the existing structure consisting of a lot of organizations and associations. These several elements form a network of responsibilities, interests and connections. This includes research and development of products. This system works all in all successfully. However, the research requirements are very complex and not uniform. In order to understand this interplay it is necessary to look at these elements in detail.

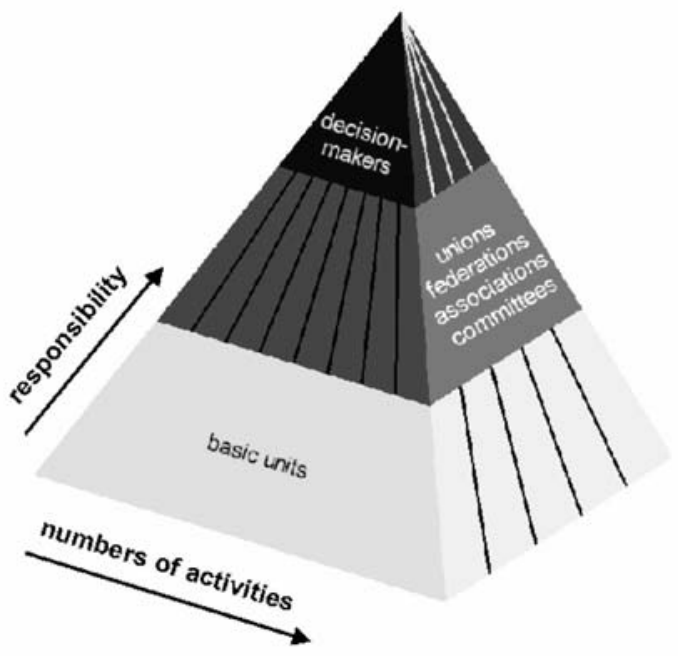

Fig. 5. Fire protection pyramid.

The fire protection network is shown symbolic in form of a pyramid in Fig. 5. It characterizes that the number of activities decreases with increasing level of responsibility. At the same time the slices which symbolize the parallel working elements (organizations etc.) are twisted against each other. This represents the high number of contacts and interactions directly or over different levels. Naturally, this is only a symbolic illustration, which shall explain the close interplay.

The question is: Why is the German fire protection successful although the structures of responsibility are this complex? The answer can be found in the fact that this complex network with multiple cross 
connections developed historically. For such networks a split responsibility is characteristic. This means that individual elements can develop successfully by themselves and provide mutual impulses. Only successful sections have positive outcomes.

Not least because of this development of subsystems, the whole system meets the target function relatively well. There is a scientific explanation from the last decades for such system behavior. The study of complex, mathematically non-linear systems, which origins from nature as well as from society, together with computational analysis and simulations showed that such systems act chaotic in a certain way. This is called "deterministic chaos". A centralized control of such system is difficult, because already slight changes in the input data can cause strong divergences in system behavior. This shows that an optimization of the system by designing the individual elements and their interaction can be quite successful.

Of course, nobody from the German fire protection society actually did such mathematical analyses, the system rather developed historically. At least, first thoughts in this direction were discussed in a "Future Workshop" of the German Fire Protection Association (vfdb) some years ago. These considerations shall show that there is no reason in Germany to radically change the system of fire protection. This is true although such conditions make it difficult to bring about positive changes in short times. For that, discussion platforms as offered by the German Fire Protection Association (vfdb) are necessary. This requires a close cooperation with political stakeholders whose importance is currently increasing because of the drastic economy in the public budgets.

Figure 5 shows the three levels in fire protection that form the pyramid. The basis corresponds to the number of activities necessary to ensure and implement fire protection as well as research or science. The low level comprises the basic institutions that are directly active for practical fire protection. These are research and education institutions, the several fire brigades, the administrative bodies in the states as well as different working committees, e.g. for standards. There are close interactions for solving fire protection problems. This shall be explained with the example of fire protection research. The public authorities express, in close interaction with the practice (fire brigades, fire fighters' schools) as well as associations from the next level, research programs for the institutes. The financing depends on the work done for these topics. For the realization as well as for the implementation of research results in practical fire protection there exist close contacts and discussions between the experts.

This interlocking and the mutual influence continues in the next level, which comprises different fire fighters' federations, also for the private and professional sector, public and private associations, like vfdb, German Institute of Standardizations (DIN), insurance federations (VdS, GDV) etc., as well as different associations of fire protection industry. To demonstrate clearly the fact that everybody interacts with everybody, the layers in each level are always twisted by $90^{\circ}$ (see Fig. 5). This continues until the top, i.e. the highest level, to which the boards of the large organizations as well as the working group of the German ministries of interior (AFKzV) belong. Here, decision making takes place and necessary laws and regulations are prepared.

In this symbolic illustration only direct fire protective facts are described, especially it does not include the interests of homeland security, civil engineering, trade and industry, environmental protection etc. But not only the public area and the associations play a big rule in the German system of fire protection. Besides, also the private sector has a big influence, especially the insurance business. Here, the fire protection relations are controlled by discounts for contracts of insurance. Likewise, the scientific thinking ahead is promoted from the point of products' development (i.e. R \& D). This concerns the own industrial research as well as the placing of research assignments to public institutions. With it, an important contribution to the development of fire safety science is made.

It is remarkable that a comprehensive control of such research is missing in both upper levels in the area of fire safety science in Germany. There is another situation in many of the remaining branches of science. For example, research in fire science is supported by different ministries like the ministry of the interior of the German states, the home office, the ministry of defense, the ministry of research and education, the economics ministry, building authorities etc. To sum up, it can be emphasized that one of the main problems in German fire research is to attract new, completely sponsored assignments with high scientific standards. The fire safety science needs a more intensive support or grant in Germany. This is the opinion of the German Fire Protection Association, which is documented in a "Memorandum about Fire Research" from 2003 [8]. 


\section{GERMAN RESEARCH INSTITUTIONS}

Reflecting the general situation in German fire protection, there are relatively small but independent research groups or institutions. They have different legal forms and organizational structures. All together, they cooperate and simultaneously compete with each other. In the sense of "self-organization", this results in a step-by-step development of the research scenery with low costs. This includes new ideas and management structures but also the usual research contents and opportunities of funding.

The money for research projects is coming as sponsorship from different offices like public sources, foundations, industry etc. Only the best can develop in an extensive way in this kind of allocation of financial resources. So there are only small fire research groups. The estimate of the author on the scope of fire research in Germany for the year 2003 is that the number of staff is about 100 with an annual budget of 5 million Euros. (The situation is not changed in the last years.) In contrast to big German research societies, like Max-Planck or Fraunhofer society, fire research is considerably dependent on separate assignments and sponsored projects. This is because research politics are not really focused on fire research and fire protection. Just recently the situation has improved by the $7^{\text {th }}$ EU Research Framework Program, which contains the focal point 10 "security". Now also the German efforts are intensified.

Research assignments by the ministries of interior of the states, the so called IMK-research, are a special feature. This is an annual program for two of the research institutions targeting practically important topics with a background in engineering and science (physics and chemistry). Altogether the fire research is practically orientated by its specific organizational form in Germany. Besides experimental investigations and tests, computer simulations on the basics of mathematical models were executed in the last two decades. Appropriate methods were developed and evaluated. From the multitude of existing research groups, a choice of these shall be introduced more detailed in the following, arranged in classes.

\section{Institutions with close relationship to vfdb}

To this class three institutions belong which have an exceptional position. All of them work very actively in the German Fire Protection Association (vfdb) and its Technical Advisory Board (TWB). In the order of presentation, they are focused on preventive fire protection, fire fighting problems and structural fire protection, naturally with a great topic overlap. On the other hand there are many traditional contacts to local partners of the respective region. The first two of these maintain a special library "fire protection" and review international literature for the use in databases. Finally, it should be mentioned that the institutions of this group try to develop a close cooperation as well as common research projects. Here, the German Fire Protection Association (vfdb) has an important function.

\section{Research Center of Fire Protection Technology (FFB), Karlsruhe}

Let us start with the host of this conference. The FFB is a pure research group, which is affiliated to the University of Karlsruhe. Founded in 1950, the center performs research to develop solutions in the field of fire protection. Primarily the treated topics belong to preventive fire safety but also to fire fighting. In addition, the center contributes to the development of national and international standards in fire safety engineering and to tests of building products and fire fighting equipment. Consultation for the industry in order to develop new products as well as fire safety concepts for buildings of special use are examples of the general service.

The research center operates a large scale testing facility (30 m long and wide and $12 \mathrm{~m}$ high, see Fig. 6). Some arrangements have been built for permanent use, so that a $10 \mathrm{~m}$ high wooden staircase, a $25 \mathrm{~m}^{2}$ burn room and several fire compartments for roof tests are available in different scales. Other test arrangements are built upon request to serve various experiments and are removed after the completion of the test series. Some specially designed small to medium scale chambers are available for tests at controlled atmosphere or for investigations of the flow and temperature patterns of plumes with a heat release rate (HRR) up to $1 \mathrm{MW}$.

The investigation of fire ignition and spread has been a key point in the center's research activities for a long time. The experimental investigation of fire growth has led to the definition of source terms for design fire. The main focus was on real fire trials. Furthermore, external fire exposure of roof coverings under the influence of wind was investigated both experimentally and theoretically. The internal fire exposure is 
shown as an example in Fig. 7. For many years the center has also been investigating the extinguishing performance of fixed sprinkler and water mist installations for a variety of applications. In the first years, research was focused on the improvement of water nozzles as well as on foam extinguishing additives. Now, an increased interest of fire services is found by the application of "Compressed Air Foam Systems (CAFS)” and water-gel substances.

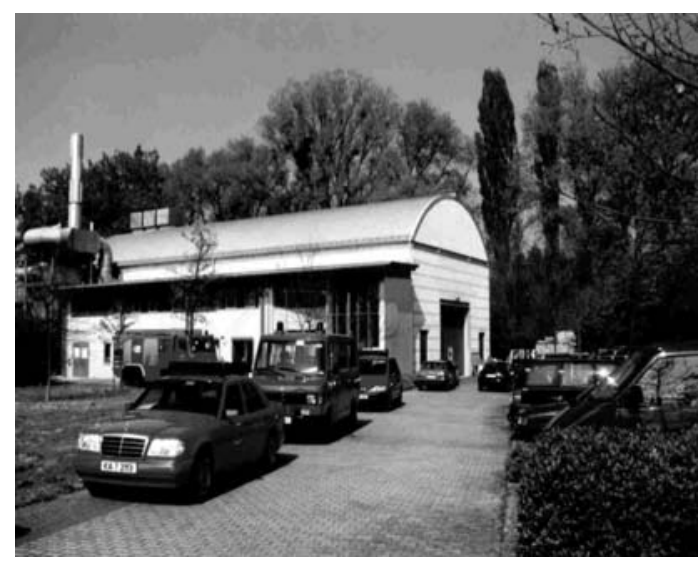

Fig. 6. Test facility in Karlsruhe.

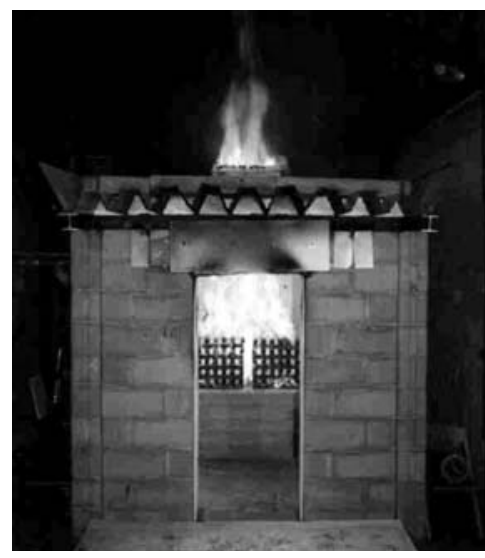

Fig. 7. Test of roof systems and elements.

\section{Institute of Fire Department Saxony-Anhalt (IdF), Heyrothsberge}

The IdF is an independent research institution located nearby the capital of Saxony-Anhalt. It is organized as a public authority of the ministry of interior in this German state. The institute does research work for all interested German parties in public and private sector. Many international contacts including Eastern Europe are cultivated. The staff is educated interdisciplinary (physicists, chemists, engineers, mathematicians, and specialists in computer science). Some scientists are trained in fire fighting as well. This institute was founded in the Eastern part of Germany 40 years ago with the objective to provide scientific knowledge as forerunner for all kinds of fire services in this country. After unification, a close cooperation with other German research institutions in the area of fire protection was quickly developed.

In the early years, the focus of investigations was on extinguishing methods and substances, especially the application of foam, as well as the development of devices for fire fighting (personal protective equipment, branch pipes etc.). One of the spectacular results was an aerosol extinguishing vehicle which generates a water mist flow up to $80 \mathrm{~m}$ long and $20 \mathrm{~m}$ in diameter by injection of water in an exhaust gas stream of a jet engine. Today a successor, called Turbolöscher, is used for film cooling of tanks in the chemical industry.

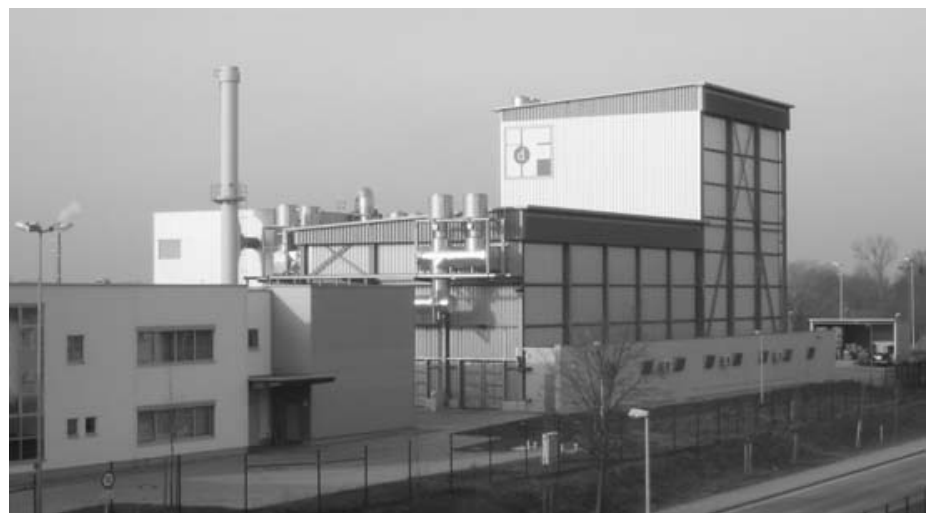

Fig. 8. Test facilities in Heyrothsberge (maximum room size: $5100 \mathrm{~m}^{3}\left(255 \mathrm{~m}^{2}\right), 3000 \mathrm{~m}^{3}\left(300 \mathrm{~m}^{2}\right)$, $500 \mathrm{~m}^{3}\left(50 \mathrm{~m}^{2}\right), 250 \mathrm{~m}^{3}\left(25 \mathrm{~m}^{2}\right)$; tunnel: $6.5 \mathrm{~m}^{2}$ x $\left.30 \mathrm{~m}\right)$. 
Current investigations are focused on a wide range of fundamental problems with practical application. For example, computer simulations of fire and extinguishing processes were carried out by CFD models (Computational Fluid Dynamics), for which a parallel computer is used. A number of studies are performed lately for a direct improvement of fire fighting. Here, it shall be mentioned: the development of different databases (e.g. for chemical substances), investigations to the thermal behavior of personal protective equipment, a task force against terrorist attacks with chemical substances including the required measuring devices for chemical analysis and others. In the last decade, investigations of different water mist systems became important. Therefore, a special LASER laboratory exists at the institute which is suitable for water mist or sprinkler nozzles up to branch pipes (see Fig. 9). This phase-Doppler-anemometer allows the measurement of droplet diameters and velocities as well as their distributions in the water-air-two-phasesystem.

A highlight at the Institute of Fire Department are new test facilities for real scale experiments, which was completed in 2003 (see Fig. 8). The testing ground consists of four fire rooms with a maximum height of $20 \mathrm{~m}$ (partly variable) and an experimental tunnel with a cross-section of $6.5 \mathrm{~m}^{2}$. The facility includes means to reduce environmental pollution resulting from fire experiments as well as some additional equipment like a jet flame (propane) with maximum height of about $20 \mathrm{~m}$. Scientifically solid conditions for fire experiments are the basic concept for this testing ground, e.g. high flexibility and reproducibility as well as exactly controllable flow into and out of the fire rooms. The new facilities are embedded in a research concept for the coming development of this institute. This comprises the following working packages of fire research:

- Compartment fires

Main topics are fires in high rack storages and fires in integrated smaller rooms (room-in-roomconcept).

- Outdoor situations with containment

The size of the fire rooms makes it possible to generate outdoor fires in a room. The objectives are exact conditions of inputs and outputs of the fire as well as the avoidance of weather influences.

- One-dimensional fire situations

This special case has a big practical importance. The influence of flow can be investigated for different situations like traffic tunnels, cable channels, ventilation shafts, and more.

- $\quad$ Simulations by gas burners

The thermal effects of a fire can be studied by propane flames. For example, the effects of a flashover or a jet of flame are interesting for fire fighters in all their details, e.g. for protective function of clothes.

- Thermal properties of materials

This is an important interface to preventive fire protection and structural fire precaution. The characteristic values can often be investigated by usual instruments in basic laboratories.

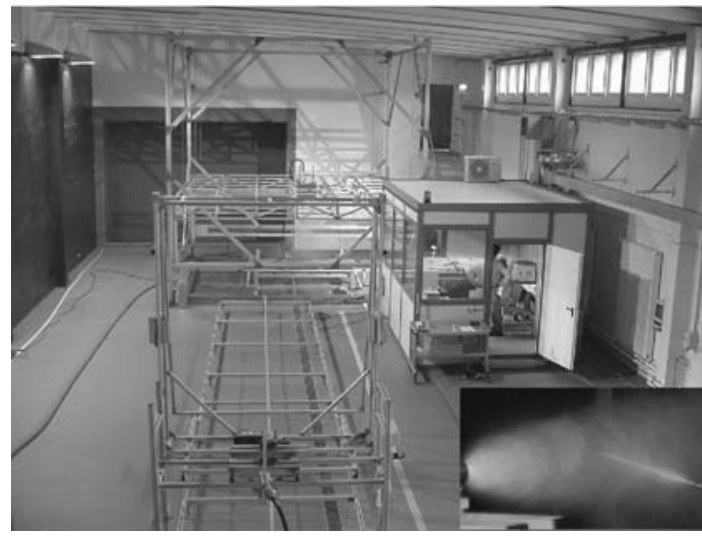

Fig. 9. Water laboratory with phase-Doppleranemometer.

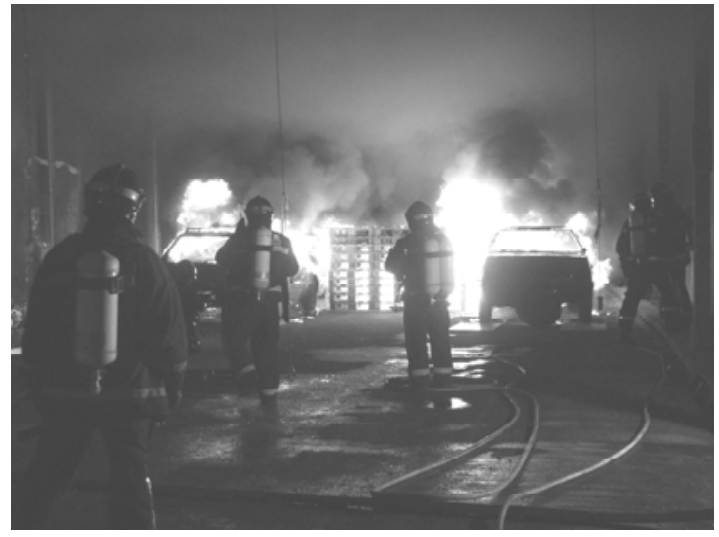

Fig. 10. Tunnel experiments with water mist in Spain. 
One current highlight in IdF research was a measuring campaign in a tunnel in Spain (San Pedro des Anes). It was proven that water mist can help to control a fire up to $120 \mathrm{MW}$, which is a typical situation for critical fires in traffic tunnels (see Fig. 10). Other interesting investigations concerned different extinguishing systems in high rack storages with different goods inside (e.g. tires). Finally, it should be mentioned that there is close cooperation to a fire fighters' school at the same location, to companies in the form of an innovation forum, and last but not least to Magdeburg universities. For instance, the institute offers lectures and practical training for bachelor and master students.

\section{Institute of Building Materials, Concrete Construction and Fire Protection (iBMB), Brunswick}

The third fire research institution in this group is a chair in this iBMB institute of the Technical University CAROLO-WILHELMINA in Brunswick, which is steeped in tradition. In the twenties of the last century, this institute was founded as a laboratory for testing of concrete and building materials. Later in the sixties, a new organizational structure was established in form of a common institute, in which the research in fire protection was intensified. At the same time, a material testing station, a so called MPA, was hived off. Up to now, both institutions closely cooperate by sharing equipment and also staff. Since 1978, the iBMB exists under this designation.

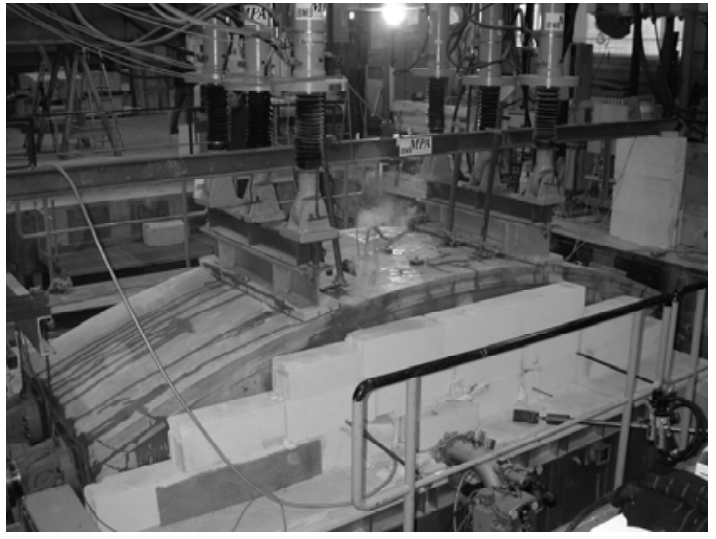

Fig. 11. Large scale fire test of tunnel shells under realistic loading.

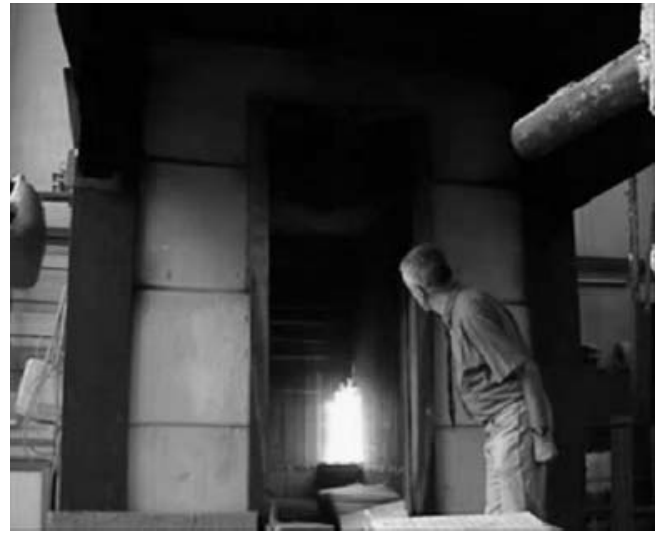

Fig. 12. Room corner test with sauna wood.

Today the iBMB consists of four departments; one of them is the "Division of Fire Protection and Fundamentals of Concrete Construction". This research team had comprehensive facilities for tests in structural fire protection at its disposal. Numerous burners and testing set-ups are located in four fire halls. Additionally, one hall is available for preparation of fire experiments (see Fig. 11, 12).

Besides specialized training of civic engineer students there are a lot of research activities, which are: fire behavior of structural systems, reaction to fires of building materials, development of innovative construction and material concepts, simulation of fire phenomena, preventive measures for special fire risks, engineering methods for proof of fire safety, input data for engineering methods, and risk-orientated structural health monitoring. Furthermore, this fire division contributes to the progress of national and international standards. Besides, there are sweeping activities to fire engineering within the German Fire Protection Association (vfdb) and in other committees of experts. Remarkable is the publication of a "Guideline on Methods of Fire Protection Engineering" under the roof of the vfdb. Furthermore, the "International Fire Protection Symposium" was organized together with the German Fire Protection Association two times in the last decade. An annual national training seminar with about 1000 participants is also carried out periodically. The scientists also provide expert opinions for court cases.

\section{Institutions with exceptional alignment}

\section{Signal Detection and Signal Processing in Technical Security Systems, Duisburg}

The main emphasis of this research group at the University Duisburg-Essen refers to automatic fire detection. Founded in 1961 in Aachen for fire detector testing in cooperation with the industry and 
insurance organizations, this group now is part of the engineering faculty in Duisburg since the seventies. International well known is this institution through AUBE ("Internationale Konferenz über Automatische Brandentdeckung”), a big international conference on the area of automatic fire detection, which was held first in 1962 and, since now, realized thirteen times, partly in cooperation with the National Institute of Standards and Technology (NIST) in Maryland USA. The research work is now continued in the department "Communication Systems" of the united University Duisburg-Essen.

In the eighties, a special laboratory for fire detection purposes was developed, which was finished as Duisburg Fire Detection Lab in 1988 (see Fig. 13). This laboratory consists of a main fire room with a base of $10.5 \mathrm{~m} \times 9.0 \mathrm{~m}$ and two observation rooms. The control units are located in both observation rooms permitting the adjustment of ceiling height in the range of $2.87 \mathrm{~m}$ to $6.57 \mathrm{~m}$. The basic measuring equipment meets the requirements of the European standard EN 54. Smoke density is measured with an ionization chamber together with a reflection type smoke densitometer. Besides, the laboratory includes a smoke duct by EN 54 part 7, which allows testing detectors on different phenomena like smoke density, heat, gases und dust. Finally, there is a wind tunnel for tests of response times of heat sensitive detectors.

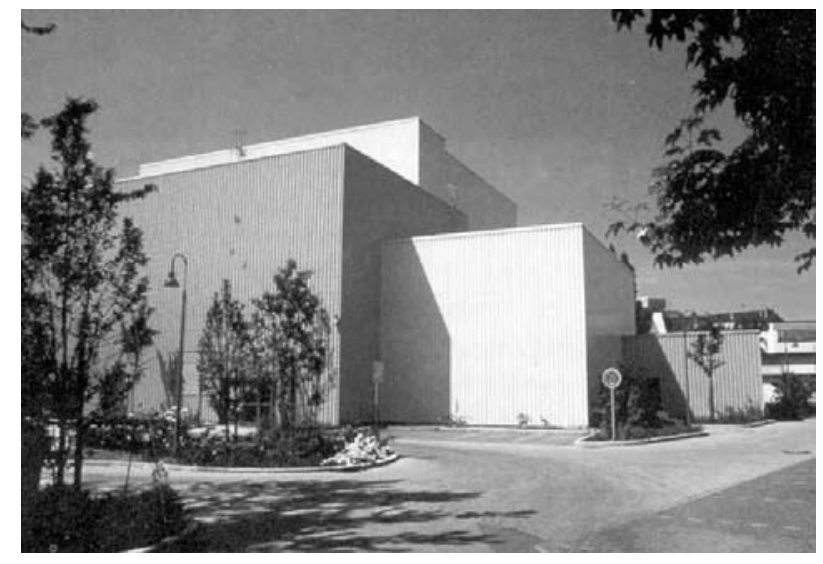

Fig. 13. Duisburg Fire Detection Laboratory.

The current research works are exemplary shown in the following. A new detection principle for cargo and cabin compartments for forthcoming Airbus aircrafts is developed, which is a modular fire and hazard detection. Furthermore, distributed sensor networks are investigated which are based on the ultra-wideband radio technology. They should be able to identify hazardous situations such as sources of fire, locate buried-alive persons, and check the status of the building construction. Finally, the investigation for an integral view on forest fires should be mentioned. This requires elaborate logistics for placing the extinguishing agents, a sufficient supply of rescue equipment and maintenance as well as a continuous observation of fire spread.

\section{Fire Engineering at the BAM, Berlin}

The Federal Institute for Materials Research and Testing (BAM) is a famous scientifically orientated engineering institution in Berlin, whose sources go back to the year 1871. Under the name BAM it has a long tradition since 1956 with a changing profile and organizational structures. The staff of 1,600 members is focused on safety in technology and chemistry. Furthermore, fire testing of building products and fire research in the construction sector has a tradition of nearly 100 years at BAM or its predecessors, respectively. Still today, fire testing is focused on the two traditional areas: reaction of building products to fire and fire resistance of construction elements.

According to BAM's new guideline "Safety in Chemistry and Technology" fire engineering has recently been identified as one of the focal points, BAM works on in interest of public safety. Therefore, in 2006, the new division "Fire Engineering" was founded as part of the department "Safety of Structures" at BAM. This division consists of the following four working groups: Behavior of Structures in Fire, Fire Scenarios and Fire Analytics, Industrial Fires, and Fire Testing for Building Materials and Construction Elements. 
The division has available a fire hall and special laboratories with burner set-ups (Fig. 14). Worth mentioning is test equipment for columns under pressure by a fire load. The current main work items are the following: development of the sub-structure technique to assess stresses and deformations of loadbearing elements, numerical simulation of thermo-mechanical coupling, application of computational fluid dynamics on fire scenarios in buildings (CFD simulations), burning rates of materials and analytics of fire gases, application of computational fluid dynamics on fire scenarios in industrial environments, selfignition and fire propagation of bulk materials, recycling products and solid fuels, reaction to fire testing of building products and other materials, and fire resistance testing of construction elements.

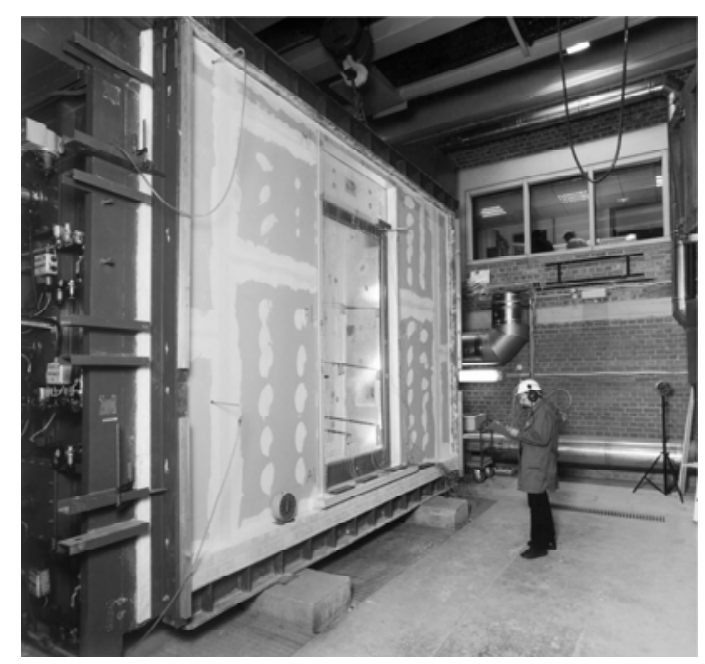

Fig. 14. Fire resistance of a fire-proof glass door in a light-weight wall construction.

\section{Other chairs at universities and academic teaching}

In Germany, many smaller groups exist which teach students on the area of fire safety or engineering, often as part of a more general course. In the following, three examples are presented, which also do fire research.

\section{Computer Applications and Integration in Design and Planning (C.I.K.), University Paderborn}

This is a division of the "Institute for Mechatronics and Constructional Techniques" of the University Paderborn, which investigates applications in computer science on the area of fire fighting. For a close cooperation to practice, a public, local oriented common group, the "Institution for Fire Fighting and Rescue Technology (IFR)" in Dortmund, was founded by local fire fighters together with C.I.K. in 2006. The main objective is to promote financed research activities, especially mission oriented research for industrial partners and public organizations. They want to contribute to expert opinions and develop research concepts. The first topic was the organization and decision support in disaster management.

\section{Course "Safety and Danger Repulse" at the Otto-von-Guericke-University Magdeburg and the University} of Applied Science Magdeburg-Stendal

Suggested and supported by the German Fire Fighters' Federation (DFV) and specific industry, above all the company Dräger Safety, a new academic course of studies was developed in Magdeburg in order to satisfy the increasing demand for safety experts in the next decades. Magdeburg was chosen because of the long tradition in education in safety and fire protection. A joint course was newly created for Bachelor or Master Degree at the "Department of Process Design and Safety" and the "Construction Department" at the Magdeburg universities. The site Magdeburg was also chosen because the above-mentioned Institute of Fire Department Saxony-Anhalt (IdF) as well as a big fire fighters' school are located in direct neighborhood. Both institutions form the "Competence Center of Fire Protection and Disaster Control” in Heyrothsberge. 
The first course of studies started in the year 2003; at present about 400 students are enrolled in this course. Besides, fire and safety research was also intensified at both universities focusing on practical problems of the industry and other partners. A close cooperation in research and teaching exists with the competence center in Heyrothsberge by lectures and practical training in scientific methods as well as in fire fighting fundamentals. Especially, scientific investigations in connection with the graduation are often carried out at the competence center. The universities have complete equipment in process engineering and fluid dynamics, e.g. a wind tunnel for flame investigations and two-phase-flows, a combustion laboratory among others with particle image velocimetry (PIV), and a cone calorimeter for investigations of important fire data.

\section{Course "Fire Protection" in the Department Safety Engineering at the University Wuppertal}

In the year 1975, the new department "Safety Engineering" was founded in Wuppertal at the "Bergische Universität” in order to develop this domain in research and teaching. The points of interest consisted of general problems of safety in production plants and in the public area. Research and teaching was focused on industrial safety, environmental protection, road safety, and quality management, but also in fire protection. Step by step a center of safety engineering was established at Wuppertal university and a special profile was formed. At present, four courses of studies are offered, which are the Bachelor in Safety Engineering and three follow-up Master Degree courses, e.g. the Master Degree in Fire Protection. In total, the department of safety engineering has about 1,000 students nowadays. A lot of special laboratories are operated at this department, out of which the laboratory of fire and explosion protection and the laboratory of hazard materials in industrial application shall be mentioned here. A main topic in research is the investigation of (industrial) dust, for which a 20 liter explosion vessel is available.

\section{ADDITIONAL REMARKS}

The industrial surrounding represents an important partner in fire safety science. Numerous different forms of cooperation, from a simple research assignment to a complete support, exist in this connection. This also follows from the fact that the German fire safety industry is very powerful and efficient. This power is demonstrated at big fairs. One of the biggest international shows is the already mentioned INTERSCHUTZ "Der rote Hahn", which is the framework for different other activities in fire protection with international effects. The next one will be held in Leipzig in the year 2010.

The German Fire Protection Association (vfdb) establishes a platform for this cooperation, allowing members from science, industrial research and development, insurance agencies as well as users to come together and exchange their opinions and ideas on a voluntary basis. The Technical Advisory Board (TWB) of vfdb consists of representatives from all these groups. Each member of TWB heads a working group that each deal with different topics of fire protection. Together, the board issues guidelines, now also in English language, as well as reports and position papers. In this way the vfdb also promotes the progress in fire research. To the same purpose the association organizes the annual conferences "vfdb-Jahresfachtagung" and International Fire Protection Symposiums (IBS). These meetings have a scientific character with a main focus towards applications.

Naturally, a reliable financing of research is extremely important. Here it has to be mentioned that funding of fire research by the German public authorities is rather low. Therefore, it is noteworthy that the German Federal Government has decided on a national security research program for the period 2007-2010. This program includes an overall funding of 123 million Euros. The security program is one of 17 innovation fields of the Federal Government's high-tech strategy. This activity is the national reflection of the EU Research Framework Program on the field of security. Therefore, the general objective of this research consists of the development of technology and fundamentals of knowledge for the protection against terrorism, organized criminality, natural disasters and industrial accidents.

\section{CONCLUSIONS}

In Germany, a complicated network is realized as result of a historic development in fire protection, which also impacts on science and research. Even though it is successful, seen as a whole, there are to solve some problems in the next years. Besides a stable financing it is above all necessary to maintain the knowledge from past experiences. Here, Germany in general as well as in fire research is facing a generation change as 
a result of sweeping retirement. Therefore, quite a lot needs to be done in highest academic education, i.e. many young scientists should attain their $\mathrm{PhD}$.

Concluding, the author wants to thank all colleagues of the mentioned institutions whose information has made possible this overview. If required, the author can send further references or contact data on request.

\section{REFERENCES}

[1] Schamberger, R., "Die Entwicklung des Brandschutzes in Deutschland“, Feuerwehr-Handbuch der Organisation, Technik und Ausbildung ( $1^{\text {st }}$ ed.), Rönnfeldt J. (ed.), Kohlhammer, Stuttgart, 2003, p. 1.

[2] Hornung-Arnegg, W., Feuerwehrgeschichte: Brandschutz und Löschgerätetechnik von der Antike bis zur Gegenwart, Kohlhammer, Stuttgart, 1995, p. 37.

[3] 150 Jahre Berliner Feuerwehr 1851-2001, FKF Media e.V., Berlin, 2001.

[4] Haase, J., Vereinigung zur Förderung des Deutschen Brandschutzes e.V. 1950-2000, Kohlhammer, Stuttgart, 2000.

[5] Deutscher Feuerwehrverband e.V., Feuerwehr-Jahrbuch 2006/07, DFV Medien GmbH, Bonn, 2007.

[6] GDV Großschadenstatistik., Gesamtverband der Deutschen Versicherungswirtschaft e. V. (GDV), Berlin, 2008.

[7] Wagner, P., „Brandstatistik - was sie leistet und leisten könnte“, Proceedings of the 57. Jahresfachtagung der Vereinigung zur Förderung des Deutschen Brandschutzes e.V., Vereinigung zur Förderung des Deutschen Brandschutzes e.V., 2008, pp. 327-376.

[8] Beard, A., „Mehr tun gegen 600 Tote und 6 Milliarden Euro Schäden pro Jahr!“, Proceedings of the 53. Jahresfachtagung der Vereinigung zur Förderung des Deutschen Brandschutzes e.V., Vereinigung zur Förderung des Deutschen Brandschutzes e.V., 2004, pp. 573-586. 